\title{
Effects of weight reduction in overweight and obese children and adolescents
}

\author{
Ralf Schiel $^{1 *}$, Mario Heinrichs ${ }^{1}$, Günter Stein ${ }^{2}$ and Antje Steveling ${ }^{3}$ \\ ${ }^{1}$ Department of Diabetes and Metabolic Disorders, Ostseebad Heringsdorf, Germany \\ ${ }^{2}$ Friedrich-Schiller-University, Internal Medicine, Jena, Germany \\ ${ }^{3}$ University of Greifswald, Internal Medicine A, Greifswald, Germany
}

\section{Introduction}

In the last decades, in many countries worldwide childhood and adolescent levels of overweight and obesity have reached epidemic status. According to "WHO European Childhood Obesity Surveillance Initiative" [1] the prevalence of overweight (including obesity) ranged from $18 \%$ to $57 \%$ among boys and from $18 \%$ to $50 \%$ among girls aged 6 to 9 years. The highest overweight prevalence was found in Southern European countries [1]. In Greece for example, the prevalence of abdominal obesity in 7-year-old children was about $25 \%$ in 2010 [2]. A lower, but still very high prevalence was found in Germany: Here, in the period from 2014 up to 2017, the prevalence of overweight/obesity was $15.4 \% / 5.9 \%$ in children and adolescents aged 3 to 17 years [3], yet no increase in the period from 2003 to 2006 was found. Similar figures were reported by Ogden, et al. [4]: In their cohort the prevalence of overweight and obesity among U.S. children/adolescents was $16.9 \%$, but there was no further increase from 2003/2004 to 2011/2012 [4]. Interestingly, in most of the countries analyzed overweight and obesity were more prevalent in lower social classes [5-7].

These relatively high prevalences of overweight and obesity have also led to significant numbers of overweight- and obesity-related comorbidities at early ages. These comorbidities include metabolic disorders such as dyslipidaemia, type 2 diabetes mellitus, arterial hypertension, liver alterations and increased inflammatory activity as well as a reduced quality of life and well-being [8-21]. In a cohort of Japanese school children there was a clear association between obesity, higher levels of lipids (triglycerides LDL-cholesterol, HDL-cholesterol) and hs-CRP as marker of inflammatory disorders [22]. In a paper published in 2018, Yu, et al. found among a cohort of 408 adolescents (mean age of 13.2 years) with a body-mass index percentile of 98.0, a prevalence of non-alcoholic fatty liver disease (NAFLD) of $26.0 \%$ [23]. Yue S, et al. also revealed that "obese children with NAFLD are more susceptible to osteoporosis than children with only obesity" [24]. In a recently published review Coakley [20], using post-mortem studies of obese children, reported on coronary atheroma and other signs of premature cardiovascular diseases ("fatty streaks were found in the coronary arteries of $50 \%$ of 2-15-year-old children, while actual coronary atheroma were found in $8 \%$ of this age group. In the 16-20-yearold group, coronary atheroma was present in 33\%", [20]). Additionally insulin resistance and a pre-diabetic state seem to be strongly associated to premature type 2 diabetes mellitus and its increasing incidence [21,25-26]. Van der Aa, et al. [27] found, in a meta-analysis of children and adolescents, prevalence rates of insulin resistance between 3.1 and $44 \%$. Although there were significant differences between the studies all results demonstrated a notably elevated prevalence rate in overweight and obese children [27].

These consequential data highlight the importance and challenge of developing improved intervention and evaluation methods for effective and long-term weight reduction programs. The risk factors must also be assessed and analyzed at a very early age. Thus it was the aim of the present trial to analyze the effectiveness of an in-house 6-week weight reduction program for overweight and obese children and adolescents in a specialized hospital. In addition to weight reduction and changes in body composition, risk factors for obesity associated co-morbidities such as blood pressure, lipids, insulin resistance and parameters of liver function were studied.

\section{Patients and methods}

Totally 124 children and adolescents with overweight and obesity successively admitted to our hospital were included in the trial (inclusion criteria: BMI [body mass index]/BMI-SDS [body mass index standard deviation score] $>97$. Percentile [Arbeitsgemeinschaft Adipositas im Kindes- und Jugendalter [AGA], 2012 and/or diagnosis for admittance: code according to ICD-10-GM-2019 "E66.0", http://www.icd-code.de/ icd/code/ICD-10-GM.html). The patients participated in a structured treatment and teaching program [STTP] for weight reduction (Arbeitsgemeinschaft Adipositas im Kindes- und Jugendalter [15,28]. The STTP was evaluated and demonstrated a good long-term effect (weight reduction and stabilization) over a period of 12 months [29,30].

\section{Structure of the STTP}

In respect of weight reduction and long-term goal achievement multicomponent interventions have been highlighted as essential for lifestyle modification (Arbeitsgemeinschaft Adipositas im Kindesund Jugendalter [15,28]. The STTP should empower patients to make behavioral changes. Strategies should include and combine aspects of diet, physical activity and weight maintenance techniques (Arbeitsgemeinschaft Adipositas im Kindes- und Jugendalter [15,28]. The STTP (Arbeitsgemeinschaft Adipositas im Kindes- und Jugendalter $[15,28]$ used in the present trial consisted of 28 therapeutic sessions

*Correspondence to: Ralf Schiel, Department of Diabetes and Metabolic Disorders, Ostseebad Heringsdorf, Germany, E-mail: r.schiel@medigreifinselklinikum.de

Received: October 15, 2019; Accepted: October 29, 2019; Published: October 31,2019 
with a duration of 45 minutes each. The main topics and techniques of the therapeutic sessions were the following:

\section{Self-esteem}

- 2 therapeutic sessions

- Brief discussion on self-esteem

- Feelings, individual goals

\section{Eating behavior}

- 10 therapeutic sessions

- Patients educated on healthy eating, portion size

- Patients taught to read and interpret food labels

- Patients trained in preparing their meals

\section{Physical activity}

- 8 therapeutic sessions

- Patients educated in healthy physical activity

- Patients trained in physical activity during daily life

- Self-monitoring

- 2 therapeutic sessions

- Food, physical activity and mood diary

- Identification of triggers influencing eating behavior, physical activity and mood

\section{Goal setting}

- 1 therapeutic session

- Encouraging patients to make short- and long-term goals, brainstorming and to define individual steps with regard to diet and physical activity

\section{Cognitive re-structuring}

- 2 therapeutic sessions

- Discussion of positive and negative thoughts and beliefs, interactions with behavioral changes, goals and strategies for maintaining weight reduction

\section{Maintenance}

\section{- 3 therapeutic sessions}

- Discussion and development of general and individual strategies for long-term weight reduction and avoiding relapse

As support of the STTP teaching materials were developed [15]. During the therapeutic sessions the children and adolescents used these materials. They used them also in homework for repetition. The details of the program and its evaluation were published by Schiel, et al. in 2008 [30].

\section{Schedule of the trial}

At the beginning of the trial and at the end of in-house rehabilitation during inpatient treatment the following examinations were performed:

1. In all patients physical examinations were performed.

2. Measurements of height and weight were assessed with patients wearing light clothing and without shoes. BMI and BMI-SDS were calculated according to the formulae "BMI $=\mathrm{kg} / \mathrm{m}^{2}$ " and "BMI$\mathrm{SDS}=\left(\left[\mathrm{BMI} / \mathrm{M}_{(\mathrm{t})}\right] \mathrm{L}_{(\mathrm{t})}-1\right) /\left(\mathrm{L}_{(\mathrm{t})}{ }^{*} \mathrm{~S}_{(\mathrm{t})}{ }^{\prime},\left(\mathrm{M}_{(\mathrm{t})}, \mathrm{L}_{(\mathrm{t})}\right.\right.$ and $\mathrm{S}_{(\mathrm{t})}$ are pre-defined parameters depending on age $e_{(t)}$ and sex (Arbeitsgemeinschaft Adipositas im Kindes- und Jugendalter [28].

3. Body composition analyses were done using a Body composition analyzer (BC418MA, TANITA Europe GmbH, Sindelfingen, Germany).

4. Blood pressure in the sitting position was measured after the patients had rested for $10 \mathrm{~min}$ by using a standard sphygmomanometer according to the World Health Organization (WHO) recommendations [31]. In all patients a 24-hour-monitoring was performed (Premo Trend, Zimmer Elektromedizin, Neu-Ulm, Germany).

5. Ultrasound examination (Siemens Acuson X300PE, München, Germany): On ultrasound images the diagnosis steatosis hepatis (fatty liver) was given, if the liver looks brighter than normal (but not lumpy or shrunken like cirrhotic livers).

Measurements of carotid intima-media thickness (IMT) were done by one physician performing 5 measurements on each side and calculating the mean. Definition of normal values was according to the German standard [32].

6. Blood-glucose (glucose-oxidase-method, Speedy, Müller Gerätebau $\mathrm{GmbH}$, Saalfeld, Germany) and HbA1c-measurements (DCA2000 method, Bayer Diagnostics, Leverkusen, Germany, following DCCTstandard $[\mathrm{HbA} 1 \mathrm{c} /$ mean normal] $\mathrm{x}$ mean according to the DCCTstandard [33]) were done directly in the laboratory of the Medigreif Inselklinik Heringsdorf $\mathrm{GmbH}$ using blood samples derived from finger pricking. Additionally venous blood samples taken in the morning of the first day after hospital admission (at onset/beginning of the trial) and at the last day of patients' in-hospital stay (at the end of the trial) following an overnight fasting period were analyzed (Laborgemeinschaft IMD, Prof. Dr. med. G. Menzel, Pappelallee 1, 17489 Greifswald, Germany) from all patients. The parameters analyzed and the methods of measurement are shown in (Table 1).

The HOMA calculation is an iterative structural model to estimate the $ß$-cell function together with insulin sensitivity. HOMA was calculated according to the formula: HOMA=(fasting plasma insulin $\mathrm{x}$ fasting plasma glucose)/22.5 (http://www.dtu.ox.ac.uk/homacalculator/ index.php, 27.06.2019).

\section{Ethics vote}

The trial was approved by the local ethics committee (Auswirkungen einer sechswöchigen spezifischen Rehabilitationsmaßnahme bei Kindern und Jugendlichen mit Übergewicht und Adipositas auf Gewichtsverlauf, Veränderungen von Risikoparametern und Mikrobiom, Reg.-No. BB 119/17, 28.07.2017, Universitätsmedizin Greifswald, Ethikkommission, Greifswald).

\section{Statistical analysis}

Statistical analysis was performed using $\operatorname{SPSS}^{\circ} 22.0$ (Statistical Package for Social Science, SPSS, Chicago, IL, USA). Values showing normal distribution were registered as mean $(\mathrm{MW}) \pm$ standard deviation (SD), non-normal distributed values were given as median and range. Comparisons were evaluated with chi-square-tests or Fisher's exact test in case of frequencies less than 5. Paired Student's t-test and Wilcoxon-tests were used to compare the mean values. Correlations were calculated according to Pearson and for multivariate analyses 
Table 1. Laboratory parameter and method of measurement

\begin{tabular}{|c|c|}
\hline Parameter & Method \\
\hline Total cholesterol (TC) & Enzymatic color test \\
\hline Low density lipoprotein (LDL) - cholesterol & Enzymatic color test \\
\hline High density lipoprotein (HDL) - cholestrerol & Enzymatic color test \\
\hline Triglycerides (TG) & Enzymatic color test \\
\hline Uric acid & Enzymatic color test \\
\hline C-reactive protein & Turbidimetry \\
\hline Creatinine & Enzymatically \\
\hline Estimated glomerular filtration rate (GFR) & $\begin{array}{l}186 \mathrm{x}(\text { creatinine }[\mathrm{mgdl}])^{-1.154} \mathrm{x}(\text { age } \\
\text { [years] })^{-0.203 * *}\end{array}$ \\
\hline Cystatine $\mathrm{C}$ & Immunoturbidimetry \\
\hline Asparte-aminotransferase (ASAT) & UV-test \\
\hline Alanine-aminotransferase (ALAT) & UV-test \\
\hline Gamma-glutamyl-transferase (gGT) & Kinetic color test \\
\hline Insuline & Chemiluminescence assay \\
\hline Thyroidea stimulating hormone (TSH)* & Chemiluminescence assay \\
\hline Free triiodothyronine (fT3)* & Chemiluminescence assay \\
\hline Free thyroxine (fT4)* & Chemiluminescence assay \\
\hline C-peptide & chemiluminescence assay \\
\hline \multicolumn{2}{|c|}{$\begin{array}{l}\text { *laboratory parameter was solely measured at onset of the trial. } \\
\text { **MDRD-formula according the recommendations of the Deutsche Diabetes- } \\
\text { Gesellschaft (DDG) (Rüster et al., 2015) }\end{array}$} \\
\hline
\end{tabular}

ANOVA models were used. Significance was set at $\mathrm{p}<0.05$. Two-tailed significance tests were used throughout.

\section{Results}

\section{Baseline characteristics}

The baseline characteristics of the patients in respect of age, sex, height, weight, BMI, BMI-SDS and duration of in-house rehabilitation are given in (Table 2). (Table 3) shows the educational levels of the 124 children and adolescents.

\section{Changes of body weight, BMI and body composition}

After an in-patient treatment lasting in the mean 5 weeks, children and adolescents reached a mean weight reduction of $4.2 \pm 3.1$ (range, $-15.9-+0.9) \mathrm{kg}(\mathrm{p}<0.001)$ accompanied by a reduction of body fat mass (Table 4). At baseline the mean weight percentile of the patients was 98.9 \pm 1.86 (range, 83.0-99.5). 8/124 (7\%) of the children and adolescents were below the $97^{\text {th }}$ percentile, $39 / 124$ (31\%) of the patients $\geq 97^{\text {th }} \leq 99^{\text {th }}$ percentile, and $77 / 124(62 \%)>99^{\text {th }}$ percentile.

\section{Analyses of risk parameters for metabolic and cardiovascular complications}

In total about $70 \%$ of the children and adolescents (87/124) showed non-normal laboratory parameters as well as higher blood pressure values and/or an increased thickness of A. carotis intima media or steatosis hepatis. Three 3 patients were treated with antihypertensive drugs (ACE-inhibitors). Mean thickness of carotid intima-media was $0.43 \pm 0.08$ (range, $0.30-0.60) \mathrm{mm}(\mathrm{n}=68) ; \mathrm{n}=46 / 68(67 \%)$ of the patients showed a normal range $(<0.45 \mathrm{~mm}), 6 / 68(8 \%)$ slightly elevated $(\geq 0.45-\leq 0.50 \mathrm{~mm})$ and $17 / 68(25 \%)$ an elevated $(>0.50 \mathrm{~mm})$ thickness (Table 5).

\section{Laboratory parameters}

\section{Lipids}

During the in-house rehabilitation there was a significant reduction in all lipid sub-groups. Moreover, the percentage of children and adolescents with concentrations of total cholesterol, LDL-cholesterol and triglycerides above the recommended level [21] decreased significantly. However, in contrast to international recommendations [21], following participation in the structured treatment and teaching program (Arbeitsgemeinschaft Adipositas im Kindes- und Jugendalter $[15,28]$ for patients with overweight and obesity, there was no increase, but a decrease of HDL-cholesterol in the present cohort (Table 6).

\section{Glucose metabolism}

At initiation of the trial 4 patients (3\%) presented with diabetes mellitus type 2 (code according to ICD-10-GM-2019 "E11.9", http://www.icd-code.de/icd/code/ICD-10-GM.html) in addition to overweight/obesity. Two of these patients had an HbAlc higher than $6.5 \%$ and all were treated with antidiabetic drugs (female, 10 years old, BMI-SDS 2.1, HbA1c 6.2\% [44.3 mmol/mol], Metformin; male, 15 years old, BMI-SDS 3.5, HbA1c $6.1 \%$ [ $43.2 \mathrm{mmol} / \mathrm{mol}]$, Metformin; female, 13 years old, BMI-SDS 2.8, HbAlc 10.4\% [90.2 mmol/mol], Metformin, insulin; male, 16 years old, BMI-SDS 3.1, HbA1c $8.3 \%$ [67.2 $\mathrm{mmol} / \mathrm{mol}]$, Metformin). In all patients fasting blood glucose levels were analyzed at the beginning of the trial. In the patients without the diagnosis of diabetes mellitus an oGTT [34] was also performed. Following the oGTT [34] there was no additional diagnosis of diabetes mellitus. However, following the oGTT [34] in 1 (1\%) patient there was a diagnosis of impaired glucose tolerance [34]. On the other hand, in $23 \%$ of the patients the values for HOMA were elevated, indicating clinically relevant insulin resistance with risk for type 2 diabetes mellitus. After rehabilitation and weight loss the percentage decreased by up to $14 \%(\mathrm{p}=0.015)$ (Table 6). The other parameters analyzed are shown in (Table 6).

\section{Parameters of liver function}

The parameters of liver function are shown in (Table 7).

\section{Correlation analyses}

In the total cohort of 124 children and adolescents with overweight and obesity there were significant correlations between BMI-SDS and body fat mass $(r=0.74, p<0.001)$, percentage of body fat $(r=0.70$, $\mathrm{p}<0.001)$, concentration of uric acid $(\mathrm{r}=0.19, \mathrm{p}=0.035)$, triglycerides $(\mathrm{r}=0.21, \mathrm{p}=0.023), \mathrm{LDL} / \mathrm{HDL}$ quotient $(\mathrm{r}=0.19, \mathrm{p}=0.044)$, eGFR $(\mathrm{r}=-$ $0.19, \mathrm{p}=0.037)$, Cystatin $\mathrm{C}(\mathrm{r}=0.23, \mathrm{p}=0.015)$, ASAT $(\mathrm{r}=0.24, \mathrm{p}=0.008)$, ALAT $(r=0.23, p=0.013)$, gGT $(r=0.26, p=0.005)$, C-peptide $(r=0.24$, $\mathrm{p}=0.008)$, insulin concentration $(\mathrm{r}=0.23, \mathrm{p}=0.013)$, $\beta$-cell function $(\mathrm{r}=0.24, \mathrm{p}=0.011)$, insulin sensitivity $(\mathrm{r}=-0.25, \mathrm{p}=0.008)$, insulin

Table 2. Baseline characteristics of 124 patients with overweight and obesity studied

\begin{tabular}{|l|c|c|c|}
\hline Paramter & MW \pm SD & Min. & Max. \\
\hline Number (n) & 124 & $/$ & $/$ \\
\hline Age (years) & $13.4 \pm 2.8$ & 6.1 & 20.1 \\
\hline Females (n [\%]) & $66(53.2)$ & $/$ & $/$ \\
\hline Duration of in-house rehabilitation (days) & $35.9 \pm 6.7$ & 22 & 57 \\
\hline Height (m) & $1.61 \pm 13,7$ & 126 & 190 \\
\hline Body weight (kg) & $88.5 \pm 27.1$ & 39,1 & 182,1 \\
\hline BMI (kg/m $\mathbf{m}^{\mathbf{2}}$ & $33.3 \pm 6.4$ & 21,6 & 50,4 \\
\hline BMI-SDS & $2.71 \pm 0.51$ & 1,5 & 4,2 \\
\hline
\end{tabular}

Table 3. Educational level of 124 patients with overweight and obesity studied

\begin{tabular}{|l|c|c|}
\hline Educational level & Number (n) & Percentage (\%) \\
\hline Special school & 11 & 9 \\
\hline Elementary school & 33 & 27 \\
\hline Medium school & 40 & 32 \\
\hline Higher school & 16 & 13 \\
\hline Vocational training/other activities & 24 & 19 \\
\hline
\end{tabular}


Table 4. Changes of weight, BMI, BMI-SDS and body composition during the period of inpatient treatment (baseline vs at the end of inpatient treatment) in 124 children and adolescents

\begin{tabular}{|c|c|c|c|c|c|c|c|}
\hline \multirow[b]{2}{*}{ Parameter } & \multicolumn{3}{|c|}{ Baseline } & \multicolumn{3}{|c|}{ At the end of inpatient treatment } & \multirow[b]{2}{*}{ p-value } \\
\hline & $\mathbf{M W} \pm$ SD & Min. & Max. & $\mathbf{M W} \pm \mathbf{S D}$ & Min. & Max. & \\
\hline Weight (kg) (n=124) & $88.5 \pm 27.1$ & 39.1 & 182.1 & $84.3 \pm 25.1$ & 37.8 & 173.5 & $<0.001$ \\
\hline BMI $\left(\mathrm{kg} / \mathrm{m}^{2}\right)(\mathrm{n}=124)$ & $33.3 \pm 6.4$ & 21.6 & 50.4 & $31.7 \pm 5.9$ & 21.8 & 48.1 & $<0.001$ \\
\hline BMI-SDS (n=124) & $2.71 \pm 0,51$ & 1.5 & 4.2 & $2.55 \pm 0.53$ & 1.3 & 4.1 & $<0.001$ \\
\hline \multicolumn{8}{|l|}{ Body composition } \\
\hline Percentage of body fat $(\%)(n=122)$ & $41.0 \pm 7.6$ & 23.3 & 62.8 & $37.9 \pm 7.0$ & 18.1 & 57.1 & $<0.001$ \\
\hline Fat mass $(\mathrm{kg})(\mathrm{n}=122)$ & $37.7 \pm 15.9$ & 12.4 & 80.8 & $33.2 \pm 13.6$ & 12.4 & 74.4 & $<0.001$ \\
\hline Fat-free mass $(\mathrm{kg})(\mathrm{n}=122)$ & $51.2 \pm 13.6$ & 26.7 & 104.5 & $51.5 \pm 13.7$ & 25.2 & 99.1 & 0.31 \\
\hline
\end{tabular}

Table 5. Laboratory values and risk parameters of 124 patients with overweight and obesity studied

\begin{tabular}{|c|c|c|c|}
\hline Paramter & $\mathbf{M W} \pm$ SD & Min. & Max. \\
\hline 24-h-blood pressure systolic (mmHg) & $130.5 \pm 11.6(n=116)$ & 102 & 160 \\
\hline 24-h-blood pressure systolic $\geq 135 \mathrm{mmHg}(\mathrm{n} / \%)$ & $41(35 \%)$ & l & l \\
\hline 24-h-blood pressure diastolic (mmHg) & $76.8 \pm 8.5(\mathrm{n}=116)$ & 58 & 110 \\
\hline 24-h-blood pressure diastolic $\geq 85 \mathrm{mmHg}(\mathrm{n} / \%)$ & $19(16 \%)$ & l & l \\
\hline Systolic blood pressure during the day period (mmHg) & $134.7 \pm 12.6(n=114)$ & 102 & 167 \\
\hline Diastolic blood pressure during the day period $(\mathrm{mmHg})$ & $80.4 \pm 9.7(\mathrm{n}=114)$ & 60 & 117 \\
\hline Systolic blood pressure during the night period $(\mathrm{mmHg})$ & $118.1 \pm 15.5(\mathrm{n}=113)$ & 92 & 186 \\
\hline Diastolic blood pressure during the night period $(\mathrm{mmHg})$ & $67.1 \pm 11.8(\mathrm{n}=113)$ & 43 & 119 \\
\hline Carotis-Intima-Media Thickness (mm) & $0.43 \pm 0.08(\mathrm{n}=68)$ & 0.30 & 0.60 \\
\hline Carotis-Intima-Media Thickness $\geq 0.45 \mathrm{~mm}(\mathrm{n} / \%)$ & $23 / 68(32 \%)$ & l & l \\
\hline Steatosis hepatis (n/\%) & $42 / 79(53 \%)$ & l & l \\
\hline
\end{tabular}

Table 6. Laboratory analyses and changes in lipid profiles, glucose metabolism, CRP, renal and thyreoidal parameters in 124 children and adolescents

\begin{tabular}{|c|c|c|c|c|c|c|c|}
\hline \multirow[b]{2}{*}{ Parameter } & \multicolumn{3}{|l|}{ Baseline } & \multicolumn{3}{|c|}{ At the end of inpatient treatment } & \multirow[b]{2}{*}{ p-value } \\
\hline & $\mathbf{M W} \pm \mathbf{S D}$ & Min. & Max. & $\mathbf{M W} \pm \mathbf{S D}$ & Min. & Max. & \\
\hline $\begin{array}{l}\text { Lipids* } \\
\text { Total cholesterol (mmol/l) }(\mathrm{n}=104)\end{array}$ & $4.42 \pm 0.71$ & 2.7 & 6.1 & $3.66 \pm 0.61$ & 2.3 & 5.1 & $<0.001$ \\
\hline Total cholesterol $\geq 5.2 \mathrm{mmol} / \mathrm{l}(\mathrm{n} / \%)$ & $17 / 104(16 \%)$ & / & / & 0 & l & / & \\
\hline HDL-cholesterol (mmol/l) $(\mathrm{n}=104)$ & $1.22 \pm 0.24$ & 0.46 & 1.94 & $1.11 \pm 0.21$ & 0.64 & 1.70 & $<0.001$ \\
\hline HDL-cholesterol < $1.0 \mathrm{mmol} / \mathrm{l}(\mathrm{n} / \%)$ & $21 / 104(20 \%)$ & / & / & $34 / 104(33 \%)$ & / & / & \\
\hline LDL-cholesterol (mmol/l) $(\mathrm{n}=104)$ & $3.02 \pm 0.69$ & 1.2 & 4.7 & $2.30 \pm 0.54$ & 1.0 & 3.7 & $<0.001$ \\
\hline LDL-cholesterol $\geq 2.6 \mathrm{mmol} / \mathrm{l}(\%)$ & 73/104 (70\%) & I & I & $29 / 104(28 \%)$ & / & / & \\
\hline LDL/HDL-quotient (n=104) & $2.58 \pm 0.80$ & 1.09 & 5.43 & $2.14 \pm 0.63$ & 0.84 & 4.06 & $<0.001$ \\
\hline LDL/HDL-quotient $\geq 2.5 \mathrm{mmol} / \mathrm{l}(\mathrm{n} / \%)$ & $55 / 104(53 \%)$ & 1 & / & $27 / 104(26 \%)$ & l & / & \\
\hline Triglycerides $(\mathrm{mmol} / \mathrm{l})(\mathrm{n}=104)$ & $1.27 \pm 0.50$ & 0.51 & 3.41 & $1.07 \pm 0.37$ & 0.50 & 2.35 & $<0.001$ \\
\hline Triglycerides $\geq 1.70 \mathrm{mmol} / \mathrm{l}(\mathrm{n} / \%)$ & $22 / 104(21 \%)$ & l & l & $5 / 104(5 \%)$ & l & / & \\
\hline \begin{tabular}{|l|} 
Glucose metabolism \\
Fasting blood-glucose (mmol/l) $(\mathrm{n}=105)$
\end{tabular} & $4.6 \pm 0.5$ & 3.8 & 6.8 & $4.4 \pm 0.6$ & 3.6 & 7.5 & 0.07 \\
\hline $\begin{array}{l}\text { oGTT: blood-glucose } 2 \mathrm{~h} \text { after glucose-loading ( } \mathrm{mmol} / \mathrm{l}) \\
(\mathrm{n}=113)\end{array}$ & $6.0 \pm 1.0$ & 3.3 & 9.1 & 1 & 1 & 1 & 1 \\
\hline HOMA $(n=102)$ & $3.91 \pm 2.74$ & 0.06 & 21.06 & $3.26 \pm 1.87$ & 0.11 & 11.81 & 0.016 \\
\hline No insulin resistancy $($ HOMA $<2.0)$ & $17 / 102(17 \%)$ & / & / & $27 / 102(26 \%)$ & / & 1 & 0.015 \\
\hline Insulin resistancy possibly (HOMA $\geq 2.0<2.5$ ) & $12 / 102(12 \%)$ & 1 & / & $14 / 102(14 \%)$ & / & 1 & 0.57 \\
\hline Insulin resistancy very likely (HOMA $\geq 2.5<5.0$ ) & $49 / 102(48 \%)$ & / & l & $47 / 102(46 \%)$ & / & 1 & 0.048 \\
\hline Insulin resistancy (HOMA $\geq \mathbf{5 . 0})$ & $24 / 102(23 \%)$ & 1 & / & $14 / 102(14 \%)$ & / & / & 0.026 \\
\hline HbA1c (\%) (n=113) & $5.47 \pm 0.63$ & 4.60 & 10.40 & $5.39 \pm 0.58$ & 4.70 & 9.00 & 0.016 \\
\hline HbA1c $>6.5 \%$ & $2 / 113(2 \%)$ & / & / & / & l & 1 & / \\
\hline HbA1c (mmol/mol) $(\mathrm{n}=113)$ & $36.4 \pm 6.9$ & 26.80 & 90.20 & $35.3 \pm 6.2$ & 27.90 & 74.90 & 0.007 \\
\hline C-peptide (nmol/l) (n=103) & $0.66 \pm 0.29$ & 0.10 & 1.89 & $0.66 \pm 0.24$ & 0.10 & 1.50 & 0.887 \\
\hline $\begin{array}{l}\text { Other parameters } \\
\text { Creatinine }(\mu \mathrm{mol} / \mathrm{l})(\mathrm{n}=103)\end{array}$ & $54.5 \pm 11.0$ & 33 & 86 & $52.8 \pm 9.8$ & 36 & 81 & $<0.001$ \\
\hline 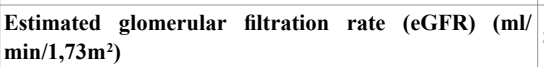 & $85.2 \pm 15.5$ & 56 & 138 & $90.8 \pm 16.2$ & 55 & 142 & $<0.001$ \\
\hline Uric acid $(\mu \mathrm{mol} / \mathrm{l})(\mathrm{n}=106)$ & $369.7 \pm 84.6$ & 52 & 628 & $333.3 \pm 85.9$ & 43 & 605 & $<0.001$ \\
\hline Hyperuricaemia $(\geq 440 \mu \mathrm{mol} / \mathrm{l})(\%)$ & $22 / 106(21 \%)$ & 1 & 1 & $11 / 106(10 \%)$ & I & / & 0.018 \\
\hline $\operatorname{CRP}(\mathrm{mg} / \mathrm{dl}) *(\mathrm{n}=118)$ & 3.28 & 0.12 & 66.1 & 0.98 & 0.12 & 21.9 & $<0.001$ \\
\hline CRP $>0.5 \mathrm{mg} / \mathrm{dl}(\%)$ & $101 / 118(86 \%)$ & / & / & $67 / 118(57 \%)$ & 1 & / & 0.007 \\
\hline TSH $(\mu \mathrm{IU} / \mathrm{ml})(\mathrm{n}=115)^{* * *}$ & $3.00 \pm 1.49$ & 0.16 & 9.30 & / & / & / & / \\
\hline Hypothyreosis $(\mathrm{TSH}>4.00 \mu \mathrm{IU} / \mathrm{ml})(\%)$ & $20 / 115(17 \%)$ & I & I & 1 & / & / & / \\
\hline fT3 (pg/ml) (n=115) & $3.83 \pm 0.64$ & 1.22 & 6.21 & / & 1 & / & / \\
\hline fT3 < $2.25 \mathrm{ng} / \mathrm{dl}(\mathrm{n} / \%)$ & $1 / 115(1 \%)$ & 1 & / & 1 & 1 & / & / \\
\hline fT4 (ng/dl) (n=115) & $1.08 \pm 0.23$ & 0.73 & 3.21 & / & / & / & 1 \\
\hline fT4 $<0.84 \mathrm{pg} / \mathrm{ml}$ & $3 / 115(3 \%)$ & 1 & / & / & / & I & / \\
\hline
\end{tabular}

*no patient was treated with lipid-lowering drugs, **in 4/124 patients (3\%) a thyreoidal disease was known (code according to ICD-10-GM-2019 [http://www.icd-code.de/icd/code/ICD-10-GM.html] 3 patients with E03.- [hyothyreosis], 1 patient with E06.3 [autoimmune thyreoiditis]), all the patients were treated with L-thyroxine 
Table 7. Parameters of liver function in 124 children and adolescents

\begin{tabular}{|l|c|c|c|c|c|c|c|}
\hline & \multicolumn{3}{|c|}{ Baseline } & \multicolumn{3}{c|}{ At the end of inpatient treatment } \\
\hline Parameter & MW \pm SD & Min. & Max. & MW \pm SD & Min. & Max. & p-value \\
\hline ASAT $(\boldsymbol{\mu m o l} / \mathbf{s l})(\mathbf{n}=\mathbf{1 0 4})$ & $0.45 \pm 0.21$ & 0.20 & 1.87 & $0.40 \pm 0.15$ & 0.17 & 1.06 & $<0.001$ \\
\hline ALAT $(\boldsymbol{\mu m o l} / \mathbf{s l})(\mathbf{n = 1 0 4})$ & $0.61 \pm 0.51$ & 0.17 & 4.00 & $0.54 \pm 0.38$ & 0.16 & 2.14 & 0.097 \\
\hline $\boldsymbol{r G T}(\boldsymbol{\mu m o l} / \mathbf{s l})(\mathbf{n}=\mathbf{1 0 4})$ & $0.39 \pm 0.28$ & 0.11 & 2.50 & $0.30 \pm 0.25$ & 0.13 & 2.08 & $<0.001$ \\
\hline
\end{tabular}

resistancy $(\mathrm{r}=0.28, \mathrm{p}=0.003)$, HOMA $(\mathrm{r}=0.22, \mathrm{p}=0.017)$, carotis intima media thickness $(\mathrm{r}=0.46, \mathrm{p}<0.001)$, steatosis hepatis $(\mathrm{r}=0.48, \mathrm{p}<0.001)$, mean systolic blood pressure during 24 hours $(\mathrm{r}=0.42, \mathrm{p}<0.001)$ and mean diastolic blood pressure during 24 hours $(\mathrm{r}=0.23, \mathrm{p}=0.013)$.

\section{Multivariate analyses}

\section{Thickness of A. carotis intima media}

The most important factors associated with thickness of A. carotis intima media ( $\mathrm{R}$-square $=0.375$ ) revealed by the multivariate analysis were: body weight at onset of the trial $(\beta=0.510, p<0.001)$, HbAlc $(B=0.440, p=0.001)$ and fasting blood glucose $(B=0.360, p=0.004)$. All other investigated parameters in the model (sex, age, height, BMI, BMI-SDS, fat mass, percentage of body fat, blood glucose after oGTT, C-peptide, insulin concentration, B-cell function, insulin sensitivity, insulin resistancy, HOMA, triglycerides, total cholesrerol, LDL- and HDL-cholesterol, LDL/HDL-cholesterol-quotient, ASAT, ALAT, gGT, uric acid, CRP, TSH, fT3, fT4, systolic and diastolic blood pressure during a 24 hours-period) showed no associations.

\section{HOMA}

Multivariate analysis demonstrated that the only factor associated with HOMA was body weight (R-square $=0.156, \beta=0.405, \mathrm{p}<0.001)$. All other parameters included in the model (sex, age, height, BMI, BMISDS, fat mass, percentage of body fat, triglycerides, total cholesrerol, LDL- and HDL-cholesterol, LDL/HDL-cholesterol-quotient, ASAT, ALAT, gGT, uric acid, CRP, TSH, fT3, fT4, systolic and diastolic blood pressure during a 24 hours-period) revealed no associations.

\section{Systolic and diastolic blood pressure}

In multivariate analyses systolic blood pressure measured during a 24-hour period was associated with BMI (R-square $=0.181, \beta=0.435$, $\mathrm{p}<0.001)$, diastolic blood pressure was associated with BMI-SDS (R-square $=0.036, \beta=0.213, \mathrm{p}=0.025$ ). The other parameters included in the models showed no associations (sex, age, height, body weight, fat mass, percentage of body fat, blood glucose after oGTT, C-peptide, insulin concentration, $B$-cell function, insulin sensitivity, insulin resistancy, HOMA, triglycerides, total cholesterol, LDL- and HDLcholesterol, LDL/HDL-cholesterol-quotient, ASAT, ALAT, gGT, uric acid, CRP, TSH, fT3, fT4, thickness of A. carotis intima).

\section{Discussion}

The prevalence of overweight and obesity in childhood and adolescence is strikingly high, and has continued to increase over the last decades in most countries [1]. In addition to this epidemiological phenomenon is the significantly increased incidence of risk profiles in children and adolescents (dyslipidaemia, type 2 diabetes mellitus, arterial hypertension, liver alterations, high inflammatory activity, reduced quality of life and well-being) [8-21]. Following these findings the American Heart Association (AHA) updated their scientific statement "Cardiovascular Risk Reduction in High-Risk Pediatric Patients" in 2019. In this new statement the authors clearly state that "the evidence base has grown sufficiently to justify the need for an updated scientific statement to guide the provider, researcher, and policy maker concerned with youth at increased risk for premature CVD" [21]. Moreover the American Heart Association strongly suggested: "Early identification and treatment are important for all youth but particularly for the high-risk patients..." [21]. In view of these recommendations, it was the goal of the present trial to analyze and identify the risk profile of overweight and obese children admitted to an in-house rehabilitation.

The results of the study were impressive: More than two thirds of all the children and adolescents who were treated during the rehabilitation had at least one risk factor at beginning of the procedure. These were either non-normal laboratory parameters or higher blood pressure values and/or increased thickness of A. carotis intima media or steatosis hepatis. In particular, increased levels of insulin resistancy (in $48 \%$ of the patients), elevated LDL-cholesterol (in $70 \%$ of the patients), fatty liver (in 53\% of the patients) and increased thickness of A. carotis intima media (in $32 \%$ of the patients) were striking. Multivariate analysis showed that the most important factors associated with thickness of A. carotis intima media were patients' body weight, $\mathrm{HbAlc}$ and fasting blood glucose. Similar results were found with regard to the HOMA index (as parameter indicating the risk for premature type 2 diabetes mellitus) and blood pressure. In both models body weight or BMI were identified as the most important factors associated. These results agree well with the literature: For at least 20 years obesity has been known to be a correlating factor with vascular fatty streaks and atherosclerotic lesions $[21,35,36]$. Also more recently published studies confirm this association [37-39]. Furthermore higher BMI is often accompanied by dyslipidemia, hyperglycemia and insulin resistance, inflammation and oxidative stress $[21,40,41]$.

During the in-house rehabilitation grogram overweight and obese children and adolescents reached a mean weight reduction of about 4 $\mathrm{kg}$, accompanied by a reduction in BMI, BMI-SDS and body fat mass. These changes were associated with an improvement in laboratory parameters (total cholesterol, LDL-cholesterol, glucose metabolism, liver enzymes). However, the follow-up period was too short to demonstrate improvements in sonographical density of the liver, in blood pressure or in carotid-intima media thickness. In children and adolescents with overweight and obesity rehabilitation has proven to be an effective therapeutic approach for weight reduction. The effectiveness of this therapy was evaluated by Schiel, et al. [15,30], but also in a German multicenter-trial by van Egmond-Fröhlich [29]. In general the weight and BMI-reduction in these studies were comparable to the effects of the present trial, but they lacked data on the improvement of risk parameters. In 2019 Ferranti, et al. conclude: “The magnitude of weight loss necessary to elicit meaningful improvement in CVD risk factors among youth with obesity has not been fully determined; a BMI reduction of $5 \%$ to $10 \%$ or 0.25 to 0.5 in BMI standard deviation score could be required". In view of this lack of evidence the American Heart Association cites the CHARON study (Hypercholesterolemia in Children and Adolescents Taking Rosuvastatin Open Label) which was able to demonstrate in children that treatment with rosuvastatin let to regression of carotid intima-media thickness $[21,42]$. Similar results in regarding risk reduction for type 2 diabetes mellitus were found in the TODAY 2 study (Treatment Options for Type 2 Diabetes in Adolescents and Youth Phase II Study) [43] or for children and adolescents with elevated blood pressure values [21].

In conclusion, the present trial demonstrates that in-house rehabilitation leads to an effective weight reduction in children and adolescents with overweight and obesity. Moreover, overweight and obese children and adolescents already show a magnitude of metabolic 
and cardiovascular risk factors. Along with weight reduction there is also an improvement regarding these risk factors. However, up today there remains a lack of data about long-term benefits. Further controlled trials are mandatory to elucidate the long-term effect in regarding body weight, BMI and BMI-SDS, but also with respect to risk factors and the development of metabolic and cardiovascular disorders.

\section{References}

1. Wijnhoven TM, van Raaji JM, Spinelli A, Starc G, Hassapidou M, et al. (2014) WHO European Childhood Obesity Surveillance Initiative: Body mass index and level of overweight among 6-9-year-old children from school year 2007/2008 to school year 2009/2010. BMC Public Health

2. Hassapidou M, Tzotzas T, Makri E, Pagkalos I, Kaklamanos I, et al. (2017) Prevalence and geographic variation of abdominal obesity in 7- and 9-year-old children in Greece; World Health Organization Childhood Obesity Surveillance Initiative 2010. BMC Public Health 17: 126. [Crossref]

3. Robert-Koch-Institut (2018) Obesity and obesity in children and adolescents in Germany. Cross-sectional results from KiGGS wave 2 and trends. J Health Monitoring p. 3 .

4. Ogden CL, Carroll MD, Kit BK, Flegal KM (2014) Prevalence of childhood and adult obesity in the United States, 2011-2012. JAMA 311: 806-814. [Crossref]

5. Lamerz A, Kuepper-Nybelen J, Wehle C, Bruning N, Trost-Brinkhues G, et al. (2005) Social class, parental education, and obesity prevalence in a study of six-year-old children in Germany. Int J Obes (Lond) 29: 373-380. [Crossref]

6. Jabakhanji SB, Pavlova M, Groot W, Boland F, Biesma R (2017) Social class variation, the effect of the economic recession and childhood obesity at 3 years of age in Ireland. Eur J Public Health 27: 234-239.

7. Almerich-Torres T, Montiel-Company JM, Bellot-Arcís C, Almerich-Silla JM (2017) Relationship between caries, body mass index and social class in Spanish children. Gac Sanit 3: 499-504.

8. Daniels SR (2009) Complications of obesity in children and adolesecents. Int J Obes 33: 60-65. [Crossref]

9. Juonala M, Magnussen CG, BerensonGS, Venn A, Burns TL, et al. (2011) Childhood adiposity, adult adiposity, and cardiovascular risk factors. N Engl J Med 355: 1876 1885. [Crossref]

10. Vander Wal JS, Mitchell ER (2011) Psychological complications of pediatric obesity. Pediatr Clin North Am 58: 1393-1401.

11. Rodriguez-Moran M, Salazar-Vazques B, Violante R, Guerrero-Romero F (2004) Metabolic syndrome among children and adolescents aged 10-18 years. Diab Care 313: 779-784.

12. Weiss R, Dziura J, Burgert TS, Tamborlane WV, Taksali SE, et al. (2004) Obesity and the metabolic syndrome in children and adolescents. N Engl J Med 350: 2362-2374. [Crossref]

13. Flegal KM, Carroll MD, Ogden CL, Johnson CL (2001) Prevalence and trends in obesity among US adults, 1999-2000. JAMA 288: 1723-1727. [Crossref]

14. Hughes JM, Li L, Chinn S, Rona RJ (1997) Trends in growth in England and Scotland, 1972 to 1994. Arch Dis Child 76: 182-189, [Crossref]

15. Schiel R, Beltschikow W, Kramer G, Stein G (2006) Overweight, obesity and elevated pressure in children and adolescents. Eur J Med Res 11: 97-101.

16. Pierce JW, WardleJ (1997) Cause and effect beliefs and self-esteem of overweight children. J Child Psychol Psychiatry 38: 645-650.

17. Warschburger P (2011) Psychological aspects of obesity. Bundesgesundheitsbl Health Research Health Protection. 54: 562-569.

18. Ravens-Sieberer U, Redegeld M, Bullinger M (2001) Quality of life after in-patient rehabilitation in children with obesity. Int J Obesity Rel Metab Dis 25: 63-65. [Crossref]

19. Schwimmer JB, Burwinkle TM, Varni JW (2003) Health-related quality of life of severely obese children and adolescents. JAMA 289: 1813-1818.

20. Coakley JC (2018) Lipids in children and links to adult vascular disease. Clin Biochem Rev 39: 65-76. [Crossref]

21. Ferranti de SD, Steinberger J, Ameduri R, Baker A, Gooding H, et al. (2019) Cardiovascular risk reduction in high-risk pediatric patients. A scientific statement from the American Heart Association. Circulation 139: e603-e634.
22. Nishide R, Ando M, Funabashi H, Yoda Y, Nakano M, et al. (2015) Association of serum hs-CRP and lipids with obesity in school children in a 12-month follow-up study in Japan. Environ Health Prev Med 20: 116-122. [Crossref]

23. Yu EL, Golshan S, Harlow KE, Angeles JE, Durelle J, et al. (2018) Prevalence of nonalcoholic fatty liver disease in children with obesity. $J$ Pediatr 207: 64-70. [Crossref]

24. Yue S, Weiran D, Yuzhen L, Pijian Y, Qiong Y, et al. (2019) Relationship between nonalcoholic fatty liver disease and bone mineral density in adolescents with obesity: A meta-analysis. Diabetes, Metabolic Syndrome and Obesity. Targets and Therapy 12: 199-207.

25. Adeva-Andany MM, Ameneiros-Rodriguez E, Fernandez-Fernandez C, DominguezMontero A, Funcasta-Calderon R (2019) Insulin resistance is associated with subclinical vascular disease in humans. World J Diabetes 10: 63-77.

26. Weihrauch-Blüher S, Wiegand S (2018) Risk factors and implications of childhood obesity. Curr Obes Rep 7: 254-259. [Crossref]

27. Aa van der MP, Fazeli Farsani S, Knibbe CA, de Boer A, van der Vorst MM (2015) Population-based studies on the epidemiology of insulin resistance in children. $J$ Diabetes Res 2015: 362375. [Crossref]

28. http://www.adipositas-gesellschaft.de/fileadmin/PDF/Leitlinien/AGA S2 Leitlinie pdf

29. Egmond-Fröhlich A van, Bräuer W, Goldschmidt H, Hoff-Emden H, Oepen J, et al (2006) Effects of a structured outpatient treatment program after inpatient medical rehabilitation in children and adolescents with obesity. Multicenter, randomized, controlled trial. Rehabilitation 45: 40-51.

30. Schiel R, Beltschikow W, Radón S, Kramer G, Schmiedel R, et al. (2008) Long-term treatment of obese children and adolescents using a telemedicine support programme. J Telemed Telecare 14: 13-16.

31. Guidelines Subcommittee (1999) 1999 World Health Organization - International society of hypertension guidelines for the management of hypertension. $J$ Hypertens 17: 151-183. [Crossref]

32. Buck M (2013) Intima Media Thickness (IMT) of the common carotid artery in healthy children and adolescents. Sonographic methodology, applicability and reference values. Dissertation, Technical University, Munich, Germany.

33. The Diabetes Control and Complications Trial Research Group (1993) The effect of intensive treatment of diabetes on the development and progression of long-term complications in insulin-dependent diabetes mellitus. $N$ Engl J Med 329: 977-986. [Crossref]

34. Nauck M, Petersmann A, Müller-Wieland D, Schleicher E, Müller UA, et al. (2018) Definition, classification and diagnosis of diabetes mellitus. In: Kellerer M, MüllerWieland D on behalf of the DDG (ed.). Practical recommendations of the German Diabetes Society. Diabetology 13: S90-S96.

35. McGill HC Jr, McMahan CA, Herderick EE, Tracy RE, Malcom GT, et al. (2000) Effects of coronary heart disease risk factors on atherosclerosis of selected regions of the aorta and right coronary artery. Arterioscler Thromb Vasc Biol 20: 836-845.

36. Berenson GS, Bogalusa Heart Study Investigators (2001) Bogalusa Heart Study: A long-term community study of a rural biracial (black/white) population. Am J Med Sci 322: 293-300. [Crossref]

37. Day TG, Park M, Kinra S (2017) The association between blood pressure and carotid intima-media thickness in children: A systematic review. Cardiol Young 27: 12951305 .

38. Dalla Pozza R, Pirzer R, Beyerlein A, Weberruß H, Oberhoffer R, et al. (2016) Beyond intima-media-thickness: Analysis oft he carotid intima-media-roughness in a pediatric population. Atherosclerosis 251: 164-169.

39. Park MH, Skow A, De Matteis S, Kessel AS, Saxena S, et al. (2015) Adiposity and carotid-intima media thickness in children and adolescents: A systematic review. BMC Pediatr 15: 161. [Crossref]

40. Skinner AC, Perrin EM, Moss LA, Skelton JA (2015) Cardiometabolic risks and severity of obesity in children and young adults. N Engl J Med 373: 1307-1317.

41. Kelly AS, Barlow Se, Rao G, Inge TH, Hayman LL, et al. (2013) Severe obesity in children and adolescents: Identification, associated health risk, and treatment approaches: A scientific statement from the American Heart Association. Circulation 128: 1689-1712. [Crossref] 
42. Braamskamp MJAM, Langslet G, McCrindle BW, Cassiman D, Francis GA, et al. (2017) Effect of rosuvastatin on carotid intima-media thickness in children with heterozygous familial hypercholesterolemia: The CHARON study (Hypercholesterolemia in Children and Adolescents Taking Rosuvastatin Open Label). Circulation 136: 359-366.
43. TODAY Study Group, Zeitler P, Hirst K, Pyle L, Linder B, et al. (2012) A clinical trial to maintain glycemic control in youth with type 2 diabetes. $N$ Engl $J$ Med 366: 2247-2256. [Crossref]

Copyright: (C2019 Schiel R. This is an open-access article distributed under the terms of the Creative Commons Attribution License, which permits unrestricted use, distribution, and reproduction in any medium, provided the original author and source are credited. 